IZA DP No. 9074

Do Parental Networks Pay Off?

Linking Children's Labor-Market Outcomes to their Parents' Friends

Erik Plug

Bas van der Klaauw

Lennart Ziegler

May 2015 


\title{
Do Parental Networks Pay Off? Linking Children's Labor-Market Outcomes to their Parents' Friends
}

\author{
Erik Plug \\ University of Amsterdam, \\ Tinbergen Institute and IZA \\ Bas van der Klaauw \\ VU University Amsterdam \\ Tinbergen Institute and IZA \\ Lennart Ziegler \\ University of Amsterdam, VU University Amsterdam \\ and Tinbergen Institute
}

Discussion Paper No. 9074

May 2015

IZA

P.O. Box 7240

53072 Bonn

Germany

Phone: +49-228-3894-0

Fax: +49-228-3894-180

E-mail: iza@iza.org

Any opinions expressed here are those of the author(s) and not those of IZA. Research published in this series may include views on policy, but the institute itself takes no institutional policy positions. The IZA research network is committed to the IZA Guiding Principles of Research Integrity.

The Institute for the Study of Labor (IZA) in Bonn is a local and virtual international research center and a place of communication between science, politics and business. IZA is an independent nonprofit organization supported by Deutsche Post Foundation. The center is associated with the University of Bonn and offers a stimulating research environment through its international network, workshops and conferences, data service, project support, research visits and doctoral program. IZA engages in (i) original and internationally competitive research in all fields of labor economics, (ii) development of policy concepts, and (iii) dissemination of research results and concepts to the interested public.

IZA Discussion Papers often represent preliminary work and are circulated to encourage discussion. Citation of such a paper should account for its provisional character. A revised version may be available directly from the author. 


\section{ABSTRACT \\ Do Parental Networks Pay Off? Linking Children's Labor-Market Outcomes to their Parents' Friends*}

This paper examines whether children are better off if their parents have stronger social networks. Using data on high-school friendships of parents, we analyze whether the number and characteristics of friends affect the labor-market outcomes of children. While parental friendships formed in high school appear long lasting, we find no significant impact on their children's occupational choices and earnings prospects. These results do not change when we account for network endogeneity, network persistency and network measurement error. Only when children enter the labor market, we find that friends of parents have a marginally significant but small influence on the occupational choice of children.

JEL Classification: $\quad$ A14, J24, J46, J62

Keywords: social networks, occupational choice, informal job search, intergenerational effects

Corresponding author:

Erik Plug

Amsterdam School of Economics

University of Amsterdam

Roetersstraat 11

1018 WB Amsterdam

The Netherlands

E-mail: e.j.s.plug@uva.nl

\footnotetext{
* We thank seminar and conference participants in Amsterdam, Braga and Ljubljana for their comments and suggestions. We further thank the National Institute on Aging (AG-9775), the National Science Foundation (SBR-9320660), the Spencer Foundation, and the Center for Demography and Ecology and the Vilas Estate Trust at the University of Wisconsin-Madison for their support in collecting and disseminating data from the Wisconsin Longitudinal Study. Only we bear the responsibility for the further analysis or interpretation of these data. Data and documentation from the Wisconsin Longitudinal Study are available at http://dpls.dacc.wisc.edu/WLS/wlsearch.htm.
} 


\section{Introduction}

Social networks are widely considered important for labor-market outcomes (Jackson, 2010). In search models social networks are typically thought of as informal job-search channel providing job searchers with either information about open vacancies or background references, recommendations and job referrals (Rees, 1966; Granovetter, 1973). Also in surveys social networks are often mentioned as one of the main channels through which job searchers find jobs (Ioannides and Loury, 2004; Holzer, 1987, 1988; Cappellari and Tatsiramos, 2013).

Quantifying social networks and their impact on labor-market success, however, has been proved difficult. First, social networks are often loosely defined and can take many shapes and forms, ranging from family members and friends to colleagues, dormmates, neighbors and ethnic minority groups. ${ }^{1}$ Second, information on social networks is rarely collected together with information on labor-market outcomes. And third, causal inference is difficult due to the potential endogeneity of network connections (Manski, 1993; Bramoullé et al., 2009).

In this paper we examine whether children are better off if their parents have stronger social networks. Specifically, we focus on the high-school friendships of parents and test whether the number and characteristics of high-school friends affect the labor-market outcomes of children. Our empirical strategy takes into account some of the selectivity effects that are common to studies on the labor-market consequences of social networks. In particular, we examine how sensitive our results are to network measurement error, network persistency and network endogeneity.

We use data from the Wisconsin Longitudinal Study (WLS). The WLS contains detailed information on a random sample of Wisconsin high-school graduates in 1957. Respondents are asked about their friendship connections

\footnotetext{
${ }^{1}$ Examples are Kramarz and Nordström Skans (2014), Cappellari and Tatsiramos (2013), Cingano and Rosolia (2012), Marmaros and Sacerdote (2006), Topa (2001) and Edin et al. (2003).
} 
in high school, which can be used to reconstruct the underlying friendship network. Respondents also report their children's occupational choice, which we measure in terms of prospective earnings and interpret as a proxy for lifetime earnings. We exploit the richness of the WLS, including information on the respondents' cognitive and non-cognitive abilities, educational attainment and other socioeconomic variables, to account for many of individual characteristics that possibly confound with friendship ties.

We start our empirical analysis by examining whether children, parents and high-school friends of parents make similar occupational choices. We do not find evidence for the presence of friendship network effects. We find positive correlations between the occupations of children and the friends of their parents, but these positive correlations disappear as soon as we account for coinciding occupational choices between parents and children. We next analyze the relationship between the number and characteristics of friends and the labor-market outcomes of children. Again, we find that the quantity and quality of friendship ties do not influence the occupational choices and earnings prospects of children, with the exception of a small and marginally significant network effect shortly after children entered the labor market.

Our paper relates to a few recent papers that focus on the impact of social networks on labor-market outcomes within an intergenerational context. Kramarz and Nordström Skans (2014) analyze the relevance of family and classroom networks for the school-to-work transition of high-school graduates in Sweden. Using matched employer-employee data taken from administrative registers, they look how own parents as well as the parents of their children's high-school classmates affect the likelihood of working at similar firms. They find that children are significantly more likely to start working at firms that also employ their parents, but not at firms that employ their classmates' parents. These family network effects are most pronounced for low-educated children. Olivetti et al. (2013) analyze the impact of family and friendship networks on female labor supply (measured at the intensive margin). Using intergenerational information taken from the AddHealth dataset, 
they estimate the extent to which the labor supply of women depends on the labor supply of their mothers and that of their friends' mothers. They find that women work more if they, as teenagers, had working mothers as well as friends with working mothers. These family and friendship network effects are equally strong. Both papers focus on network ties between children and their parents, and between children and their classmates and friends; we focus on network ties between children, parents and their parents' high-school friends. The implications are, therefore, different. If, for example, old-boys networks are important in determining the labor-market outcomes of children, we expect that networks based on parents and their high-school friends are more suited to pick this up than networks based on children and their friends' parents.

Our paper also contributes to a larger literature in economics on the intergenerational effects of economic outcomes. In the context of labor-market outcomes, there are many empirical studies that report strong and positive associations between earnings and occupational choices of parents and their children (Solon, 1992; Björklund and Jäntti, 1997; Lentz and Laband, 1989; Laband and Lentz, 1992). In recent years, a growing number of studies have put more emphasis on causal intergenerational effects reporting substantially smaller parental effect estimates, thus revealing the importance of heritability and other selection effects (Behrman and Rosenzweig, 2002; Plug, 2004; Holmlund et al., 2011).

The remainder of this paper is organized as follows. Section 2 describes the data. We define measures for size and quality of a friendship network and discuss the earnings score as labor-market outcome. Section 3 presents the estimation results. In Section 4, we conduct several robustness tests to account for network endogeneity, network persistency and network measurement error. Finally, Section 5 concludes. 


\section{Data and descriptive statistics}

The Wisconsin Longitudinal Study (WLS) provides detailed survey data on 10,317 individuals who graduated from high school in 1957, which constitutes a random one-third sample of all graduates in Wisconsin in that year. Individuals have been interviewed during six waves (1957, 1964, 1975, 1992, 2004 and 2011) to collect detailed information on education, labor-market outcomes and measures of cognitive and non-cognitive skills. In 1975, 18 years after college graduation, individuals were asked to list their high-school friends. And in later waves respondents were also asked about basic characteristics and some labor-market outcomes of one of their (randomly selected) children. We use information information on the 6,481 children included in the 2004 wave. $^{2}$ Table 1 provides summary statistics for the main variables we use in our analysis.

\subsection{Occupations and earnings scores}

We focus on the primary occupations of respondents and their children. Occupations of parents (i.e. respondents) are measured in 1992, whereas those of children are taken from the 2004 survey. WLS respondents are between 52 and 55 years old in 1992. The age of their children ranges from 28 to 50 years in 2004, with an average of 38 years. This avoids measuring occupations at the beginning of a working career for children and at the end of a working career for parents and their friends, which may be less representative for individual employment histories. Previous studies have shown that current income within this range proxies lifetime income most accurately for the US (e.g. Haider and Solon, 2006).

In the WLS, occupational choices of respondents and their children are coded in line with the definitions of the US census in 1990. We use two

\footnotetext{
${ }^{2}$ Reasons for the difference between the initial number of respondents and the number of children in the 2004 survey include childlessness, usual sample attrition, and in some cases refusal to answer the WLS questionnaires.
} 
classification schemes in our analysis. The first classification summarizes occupations into 18 distinct categories. Corresponding frequency distributions for both respondents and their children can be found in the appendix (Table A.1). The second classification summarizes occupations into 501 distinct categories. In the latter case, the WLS provides various measures of occupational prestige, such as educational requirements and average earning prospects. We focus on the occupational earnings score, which indicates the fraction of workers in a given occupation earning at least $\$ 14.30$ per hour in 1989 according to 1990 US census data. A comparison between the respondents' annual earnings (defined as the sum wages, salaries, commissions, and tips before taxes and other deductions) and earnings scores in 1992 shows that both measures are strongly correlated. ${ }^{3}$ Thus, the occupational earnings score can be regarded as a good proxy for labor-income prospects.

Using earnings scores has several advantages in the analysis of occupational choices. First, it provides a continuous measure of the average returns to occupational choices. Since the earnings score is the same for all workers in a given occupation, the measure abstracts from earning differences due to individual heterogeneity and quantifies the potential payoff independent of worker-specific skills. This reduces the threat of biased estimates because of correlations between unobserved ability and earnings. Second, and more importantly, the earnings score can be interpreted as a proxy for lifetime earnings. Occupational choices are not only evaluated in terms of current payoffs but with respect to the average earnings across all workers in the US census. Interpreting the score as measure of lifetime earnings implicitly assumes that the occupation does not change considerably during the life cycle with respect to prospective earnings. A comparison between reported occupations in 1992 and 2004 shows that the earnings scores vary only modestly, with correlation coefficients of 0.72 and 0.49 for parents and children,

\footnotetext{
${ }^{3}$ The correlation between workers' annual earnings and earnings score in 1992 is 0.46 with a p-value less than 0.001. Because actual earnings are not reported for children of respondents, we cannot compute the same correlation for this generation.
} 
Figure 1: Occupational earnings score distribution

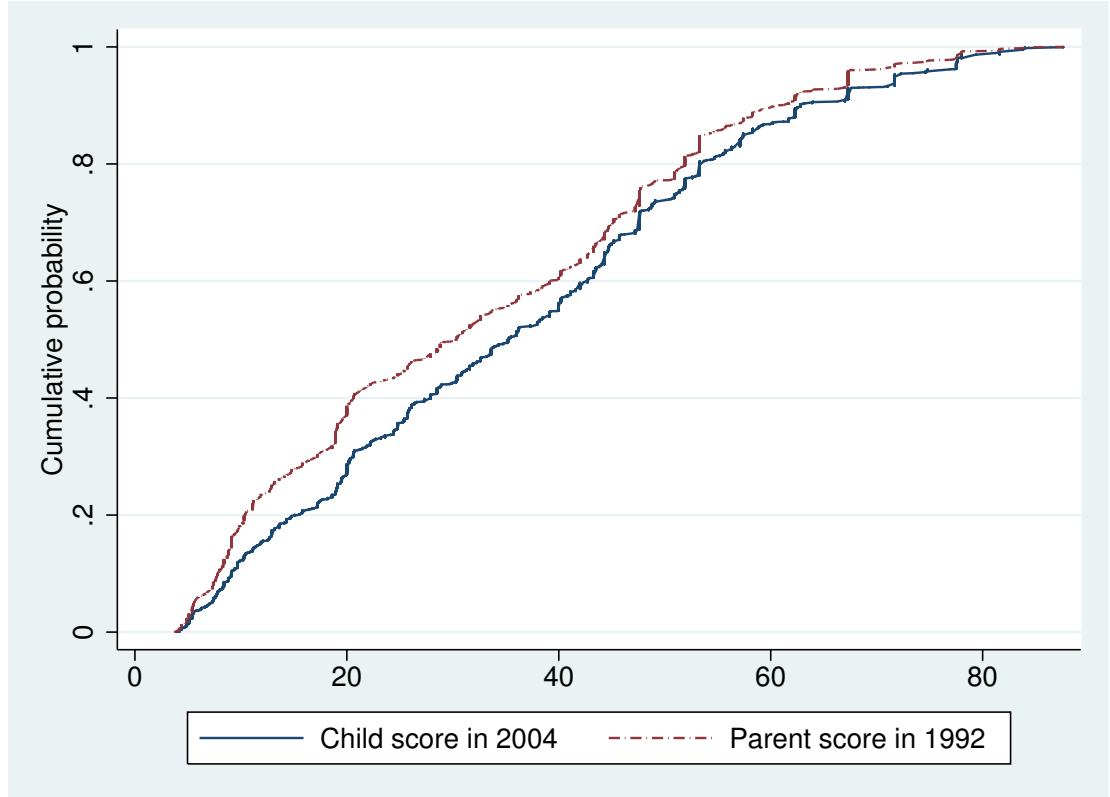

respectively.

As shown in Table 1, the earnings score averages are 35.9 and 32.5 percentage points for children and parents, respectively. A difference-in-means test confirms that the younger generation works in occupations with significantly higher earnings scores $(p<0.0001)$, suggesting intergenerational differences in occupational choices. ${ }^{4}$ To get a better idea of the distribution of earnings scores, Figure 1 plots the cumulative distribution for children and parents. It shows that earnings scores vary between the 4 th and the 88th percentile and are relatively equally distributed apart from a slightly concave shape at higher percentiles. Compared to actual annual earnings of WLS respondents, the distribution of earnings scores is by construction smoother and has no outliers.

\footnotetext{
${ }^{4}$ Comparing earnings scores between children and parents of the same wave, in 1992 or 2004, leads to similar results.
} 
Table 1: Descriptive statistics

\begin{tabular}{lcccccc}
\hline & \multicolumn{2}{c}{ All } & \multicolumn{2}{c}{ Mothers } & \multicolumn{2}{c}{ Fathers } \\
\hline \hline & Mean & SD & Mean & SD & Mean & SD \\
Child outcome & & & & & & \\
Earning Score 2004 & 35.88 & 20.31 & 35.46 & 20.41 & 36.35 & 20.18 \\
& & & & & & \\
Child characteristics & & & & & & \\
Female & 0.49 & 0.50 & 0.49 & 0.50 & 0.48 & 0.50 \\
Age (in 2004) & 37.97 & 4.10 & 38.82 & 4.00 & 37.00 & 3.99
\end{tabular}

\section{Parent characteristics}

\begin{tabular}{lcccccc} 
Female & 0.53 & 0.50 & 1.00 & - & 0.00 & - \\
Age (in 1992) & 53.13 & 0.48 & 53.08 & 0.45 & 53.19 & 0.52 \\
Earning Score 1992 & 32.54 & 20.41 & 24.13 & 17.97 & 41.94 & 18.82 \\
Years of College & 1.88 & 2.71 & 1.46 & 2.37 & 2.35 & 2.97 \\
IQ Score & 102.12 & 14.37 & 102.08 & 13.84 & 102.17 & 14.93 \\
Extraversion Score & 3.91 & 1.03 & 3.96 & 1.04 & 3.86 & 1.01 \\
Agreeableness Score & 4.87 & 0.76 & 4.99 & 0.71 & 4.73 & 0.77 \\
Conscientiousness Score & 4.88 & 0.76 & 4.90 & 0.75 & 4.86 & 0.78 \\
Neuroticism Score & 3.10 & 1.07 & 3.22 & 1.09 & 2.97 & 1.04 \\
Openness Score & 3.88 & 0.94 & 3.82 & 0.94 & 3.95 & 0.93 \\
& & & & & & \\
\hline$N$ & 5290 & \multicolumn{7}{c}{2791} \\
\hline \hline
\end{tabular}




\section{$2.2 \quad$ Friendship measures}

In 1975, respondents are asked to list the three best same-sex friends from their high-school senior class. The WLS contains information about the number of claims that can be matched to other high-school graduates in the cohort. ${ }^{5}$ Some of the claims are matched to other high-school graduates in the WLS, which allows us to reconstruct substantial parts of the friendship network in high school. ${ }^{6}$ Because the WLS sample represents a one-third share of all Wisconsin high-school graduates in 1957, survey data on characteristics of friends are available for approximately this fraction of friendship claims. According to previous research (Ennett and Bauman, 1996), US students form the majority of friendships within high school. Thus, the claims should capture the respondents' friends in 1957 reasonably well.

For each respondent in the WLS, we observe friendship links that are claimed by the individual (outgoing connections) as well as links with the individual that are claimed by other respondents (incoming connections). Borrowing the terminology of graph theory, we call the number of outgoing connections in-degree and the number of incoming connections out-degree. Furthermore, we observe whether connections are reciprocal and claimed by both sides (reciprocated connections). These friendship connections are arguably stronger and more persistent than non-reciprocated connections and can be used to measure network effects for two different strengths of friendship ties. ${ }^{7}$ Next, we construct a measure that takes all connections of

\footnotetext{
${ }^{5}$ In some cases, this number deviates from the number initially reported if respondents cannot remember their friend's full name, misspell the name or claim by mistake friends outside the cohort.

${ }^{6}$ Conti et al. (2013) use this feature of the WLS friendship data to study the impact of popularity on labor-market outcomes.

${ }^{7}$ Similarly, social-network theory distinguishes between weak and strong connections to qualify interpersonal ties. According to the weak tie hypothesis initiated by Granovetter (1973), weaker connections are more relevant for the impact of social networks since also individuals outside the direct social environment can be reached. Other studies (e.g. Krackhardt, 1992), however, argue that strong ties are of prior importance since more interaction takes place and more information is transmitted among these connections.
} 
Figure 2: Friendship ties in the network of Wisconsin high-school graduates

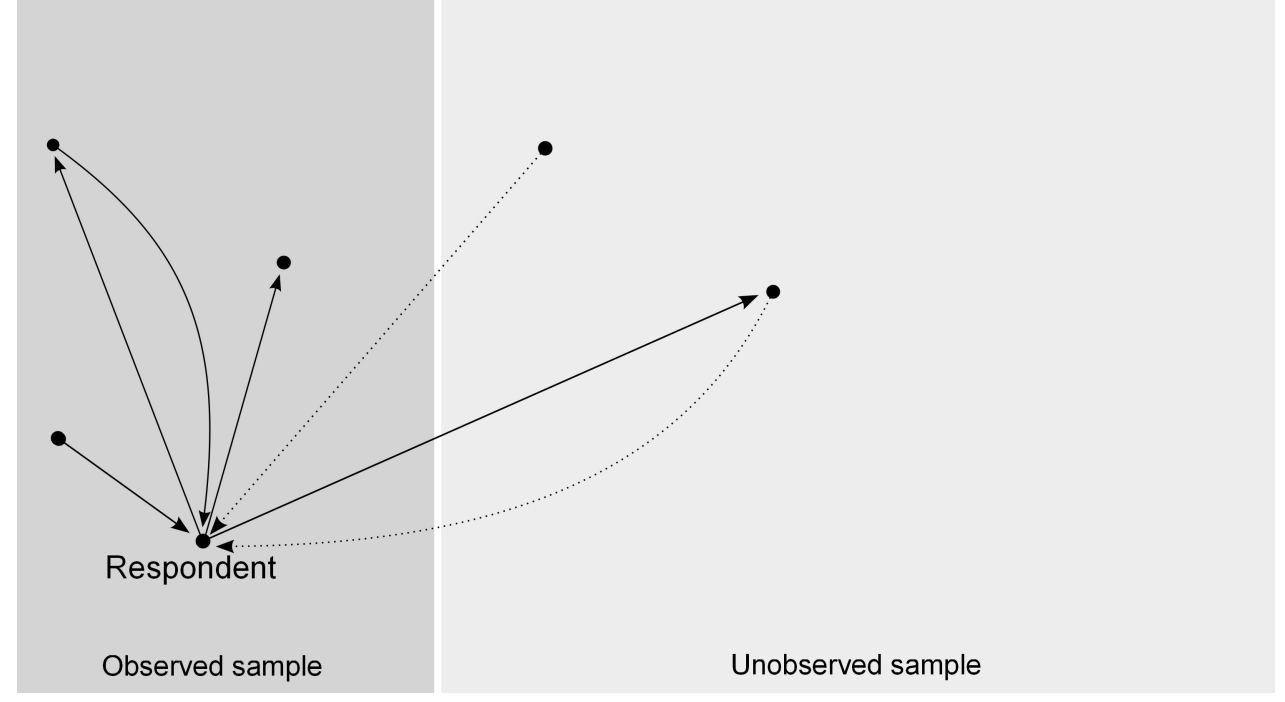

a respondent in high school into account (total friendship connections). It is defined as the sum of out-degree and in-degree connections corrected for double counting of the reciprocated friendship connections.

These friendship measures are subject to systematic measurement error. In particular, the observed in-degrees are incomplete because the WLS data cover only one-third of all potential high-school friends. Whether a respondent is claimed as friend is only observed for connections who are interviewed by the WLS. As a result, complete coverage of reciprocal friends and total friendship connections are not available. To illustrate this, Figure 2 depicts an example of a high-school graduate who claims three friends and is also claimed as friend by three other individuals. The in-degree is in this case not fully observed since some friendship connections are outside the WLS. Also, we do not observe for all claimed friends whether they are reciprocal.

Given that respondents with high in-degrees are more likely to have unobserved claims, missing observations introduce non-classical measurement error to the size of the network, which may lead to biased regression estimates. To correct the friendship measure for this error, we impute the expected number of received friendship claims based on the observed distri- 
bution and selection probability for each potential claim. As respondents can only claim same-sex friends, the imputation is done separately for the network of female and male friends. Let $p$ define the share of Wisconsin high school graduates in 1957 who are not part of the WLS. Moreover, assume that the true in-degree for individual $i$ is described by the variable $i n_{i}$, which takes values $k=0,1,2,3, . ., n$. Then, the observed measure can be expressed as $\tilde{i n}_{i}=i n_{i}-b$, where $b \sim \operatorname{Binomial}\left(i n_{i}, p\right)$. To correct the in-degree, we first impute the distribution of $i n_{i}$ based on the distribution that can be observed for $\tilde{i n}_{i}$. Denote the observed share of $k=0,1,2,3, . ., n$ claims as $\tilde{q}_{k}$ and the underlying shares as $q_{k}$. Then, the observed shares $\tilde{q_{k}}$ are predicted by the true shares by $\sum_{l \geq k}^{n}\left(\begin{array}{l}l \\ k\end{array}\right) q_{l}(1-p)^{k} p^{l-k}$. To estimate $q_{k}$, we minimize the squared difference between observed shares and their predictions subject to the constraints that the underlying $q$ 's sum to one and are bounded between 0 and 1:

$$
\min _{\left\{q_{0}, . ., q_{n}\right\}} \sum_{k=0}^{n}\left[\tilde{q_{k}}-\sum_{l \geq k}^{n}\left(\begin{array}{l}
l \\
k
\end{array}\right) q_{l}(1-p)^{k} p^{l-k}\right]^{2} \text { s.t } \sum_{l=0}^{n} q_{l}=1 \text { and } 0 \leq q_{k} \leq 1 \forall k
$$

Since friendship information is available from 9138 respondents out of approximately $3 \times 10,317$ high-school graduates in 1957 , the probability that a graduate is not observed amounts to $p=1-\frac{9138}{3 \times 10317} \approx 0,705 .^{8}$ The potential number of received claims $(n)$ can theoretically be as large as the whole population minus one. Given that we only observe up to six received claims (i.e. $\tilde{q}_{k}=0 \forall k>6$ ), the optimization becomes less precise if many (or all) potential $q$ need to be estimated. Therefore, we assume that the maximum number of potential friends is 43 , which corresponds to approximately $25 \%$ of the average size of a school cohort in the WLS. Because the probability of having more than 43 friends is very close to zero, imposing this restriction barely affects our results. Finally, the imputed shares $\left\{\hat{q}_{0}, . ., \hat{q}_{43}\right\}$ are used to calculate the expected in-degree of each respondent based on the observed

\footnotetext{
${ }^{8}$ We have to assume that non-response is uncorrelated with the number of friendship connections.
} 
number of received claims $k$ :

$$
\hat{i n}_{i}(k)=\sum_{l \geq k}^{43}\left(\begin{array}{l}
l \\
k
\end{array}\right) l \hat{q}_{l}(1-p)^{k} p^{l-k}
$$

For respondents who claim friends that are not covered by the WLS sample, also the number of reciprocal friends is measured with non-classical measurement error. Therefore, we impute the expected number of reciprocal connections exploiting the fact that friendship ties conditional on the number of claims are missing at random. Again, expected values are calculated separately for female and male friends. The dynamic imputation procedure consists of five steps and solely relies on information about observed reciprocal behavior.

First, respondents are sorted according to the number of claimed friends $\left(s_{i}=0,1,2,3\right)$. Next, we calculate the respective average number of reciprocal friends $\left(\bar{r}_{s}\right)$ for the subset of respondents with all connections in the sample. This information is used to impute expected reciprocated friendships $\left(\hat{r}_{s, i}\right)$ for individuals with one missing claim. After using the imputed values to update the averages $\bar{r}_{s}$, we estimate the expected number for respondents with two missing claims. Finally, $\bar{r}_{s}$ is updated again and used to impute values in case that all three claims are not observed. ${ }^{9}$

Table 2 provides summary statistics on the number of connections (network size) for each of the four friendship measures in the top panel. As shown in the first row, respondents claim, on average, 2.25 friends with a standard deviation of almost one friend. However, less than half of these claims are actually reciprocated. Contrary to that, the average number of received friends (in-degree) is similar to the out-degree but shows a higher variation as the number of claims is not restricted to three friends in this case. The last row summarizes the distribution of total connections, showing that

\footnotetext{
${ }^{9}$ The imputation procedure could be extended by additionally considering observable characteristics (see Conti et al., 2013) or the order of claims. Yet, a further differentiation between friendship ties would lead to less accurate estimates because they are based on only few observations.
} 


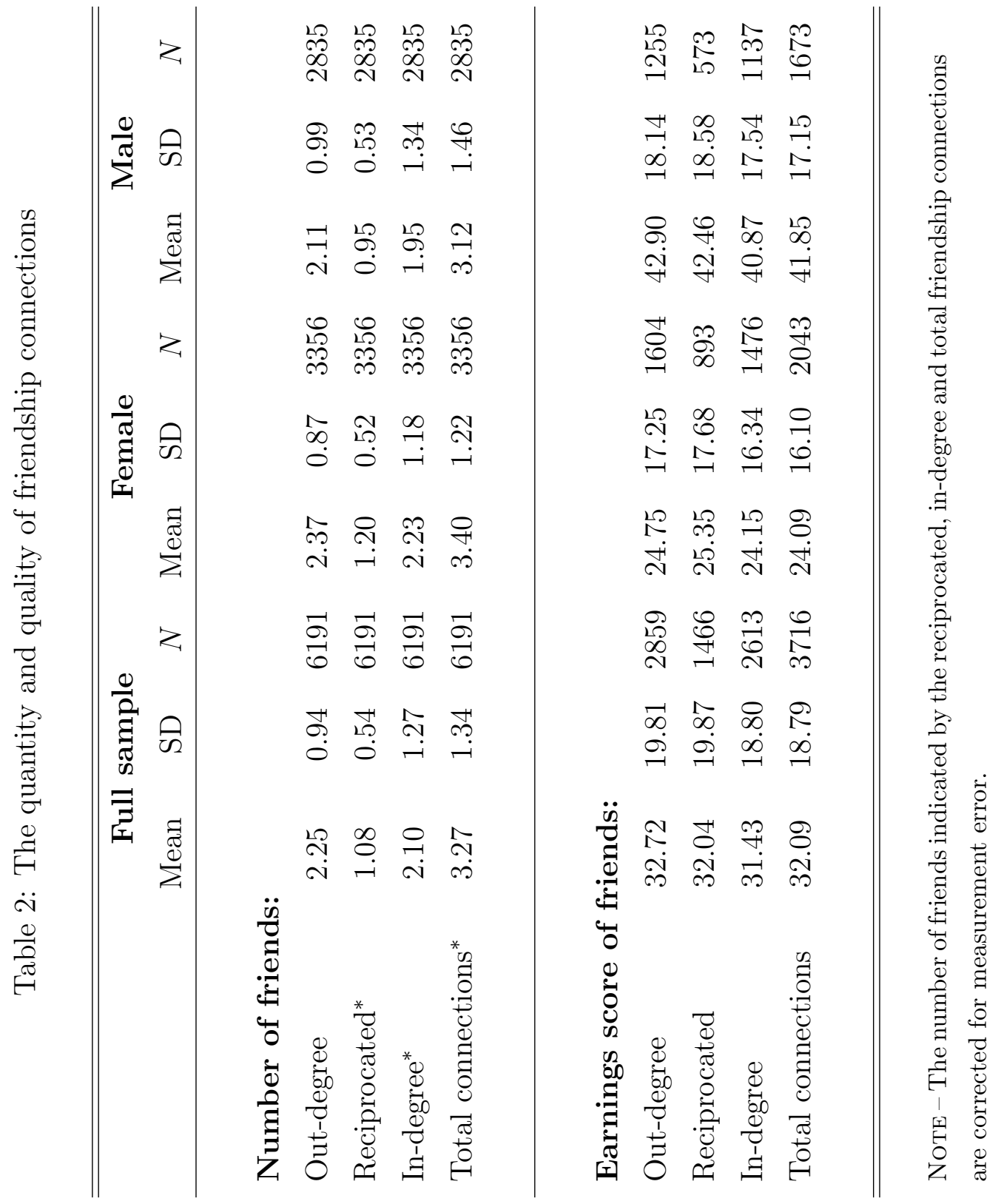


an average individual is connected to 3.27 high-school friends. Furthermore, we observe that the average number of connections differs with respect to gender. According to all four friendship measures, female respondents have more connections than males.

In addition to the number of ties, our network analysis also explores data on observed earnings scores of friends in 1992. As social contacts with high earnings scores might be better able to assist children in finding equally wellpaid jobs, this variable can be regarded as a proxy for the quality of the network. For each of the four friendship measures, we compute the average earnings score across all observed connections. ${ }^{10}$ Here systematic measurement error is less of a concern. Although not all high-school graduates are interviewed and information on earnings scores is only available for some friends, the friendship data are missing at random conditional on the number of connections because respondents are selected randomly. This means that our measure of friendship quality is an unbiased measure of network quality. ${ }^{11}$

Table 2 also provides summary statistics for the average earnings score in all friendship categories in the bottom panel. Earnings scores of outdegree connections are, on average, somewhat larger than those of reciprocal or in-degree friends. This suggests that WLS respondents tend to claim connections that are successful on the labor market. A comparison by gender shows that earnings scores of female networks are considerably lower.

\footnotetext{
${ }^{10}$ We have experimented with alternative friendship quality measures such as the maximum earnings score of friends. Our friendship quality results are insensitive to the quality measures we use and are not reported.

${ }^{11}$ There is another issue of sample selection; that is, respondents with more friends are over-represented because characteristics of friends are less likely missing. Of course, missing earnings scores could also be imputed based on available data. This requires additional assumptions on the earnings score distribution across friends. If we assume linear dependence between the earnings scores of a respondent's friends, we can impute values for all friendship claims and test the sensitivity of our network quality results. We find that our results do not change in any meaningful way.
} 


\subsection{Individual characteristics}

The WLS includes some information both on respondents and their children. Table 1 shows that children are, on average, better educated than their parents and that most of them work. Only $11 \%$ of WLS respondents report that their children are not working.

The WLS contains information on cognitive and non-cognitive skills of the respondents. Cognitive skills are measured in the 1957 wave by means of the Henmon-Nelson Test of Mental Ability. The test score results are converted to standard IQ scores. Non-cognitive skills are assessed in the 1992 wave, together with information on the respondents' labor-market careers, based on the Big Five Inventory (BFI) developed by John et al. (1991). Five personality traits (openness, conscientiousness, extraversion, agreeableness, and neuroticism) are taken from five to seven questionnaire items for each trait, where the magnitude of these item attributes are measured on a one to six scale. Using this information, we calculate average scores for each personality trait. To avoid imprecise measurement, scores are coded as missing if respondents answer less than two items per attribute. According to the Five Factor model, the combination of these traits provides a proficient summary of individual personality (Goldberg, 1990; Costa Jr and McCrae, 1992). In our analysis, we think of these cognitive and non-cognitive skill variables as fixed when parents form their friendships.

\section{Empirical analysis}

\subsection{Occupational choice}

Table 3 reports the observed matches in main occupations between children and their parents and between children and the high-school friendship connections of their parents. Matches refer to those children who work in the same occupation as their parents and as their parents' friends. Occupations are 
based on the 18 main occupation categories. ${ }^{12}$ When focusing on the friendship connections of parents, we divide for each child the number of matches by the number of friendship connections. The reported shares represent averages across all individuals. Furthermore, we report matching shares for in- and out-degree connections separately. We further compare the observed matching rates to those that would result from random matching. Assuming that occupational choices are random draws from the empirical distributions for children, parents and parents' friends, we randomly assign occupations to individuals of each subgroup and calculate the random matching shares. This procedure is repeated 100,000 times. The average random matching shares are then used to test whether observed shares are statistically larger.

We find that in $17 \%$ of all cases, the occupation of parents and children match. This is significantly different from the $12 \%$ matches that would occur if parents and children would randomly choose their occupations. The observed matching shares with the parents' friends of $14 \%$ is considerably lower but still significantly different from the random matching share, regardless of the type of friendship connections. We find that differences in matching shares between out-degree and in-degree friendship connections are remarkably small.

One explanation for the observed matches with parents' friends might be that occupational choices of the friends are correlated with those of the parents, and thus simply proxy the direct intergenerational link. To account for this possibility, we additionally calculate the matching shares between children and friends for the subsample of children who do not work in the same occupation as their parents. We find that the matching shares fall to $12 \%$, which resemble the random matching shares. This suggests that children are significantly more likely to end up working in occupations in which their parents work, but not in occupations in which their parents'

\footnotetext{
${ }^{12} \mathrm{An}$ analysis based on the more detailed occupation codes leads by construction to very few matches, which makes a reliable evaluation difficult. In the next subsection we return to the detailed occupational codes.
} 
Table 3: Observed and random matches with main occupations of children

\begin{tabular}{lccc}
\hline \hline Share of matches with.. & Observed matches & Random matches & $p$-value \\
\hline Parent & 0.173 & 0.119 & 0.000 \\
Friends of parent & & & \\
Total connections & 0.138 & 0.123 & 0.003 \\
Out-degree & 0.140 & 0.124 & 0.006 \\
In-degree & 0.141 & 0.123 & 0.003 \\
Friend of parent if parent's occupation different & \\
Total connections & 0.119 & 0.116 & 0.294 \\
Out-degree & 0.122 & 0.117 & 0.239 \\
In-degree & 0.119 & 0.116 & 0.305 \\
\hline \hline
\end{tabular}

NOTE - The $p$-value corresponds to a one-sided t-test of the hypothesis that observed matching rates exceed random matching rates.

friends work once the occupation of parents is taken into account.

\subsection{Earnings score}

While children do not choose the same occupations as their parents' friends (once we account for the occupational choices of parents), it does not mean that parents' friends do not have any influence on the labor-market outcomes of children. The parents' friends might, for instance, help or motivate children to get into better-paid occupations other than their own. To examine such a potential payoff of friendship connections, we estimate a linear relationship between the prospective earnings of children and the friendship network of parents of the following form

$$
Y_{i}^{c}=\alpha+\beta F N_{i}+\delta X_{i}^{c}+\gamma X_{i}^{p}+u_{i}
$$

where $Y^{c}$ is the earnings score of child in family $i$ and $F N$ is the friendship network measure of the parent. Our parameter of interest is $\beta$ which captures 
the network effect on the child's earnings score. We estimate the model using OLS. To give a causal interpretation to $\beta$, the friendship network should be independent of the error term $u_{i}$ conditional on the observed characteristics of the child and the parent ( $X^{c}$ and $X_{p}$, respectively). The observed characteristics should thus include variables which are related to the formation of a friendship network, which are probably other characteristics than just the basic characteristics such as gender and age. In the estimation, we use varying sets of observed characteristics including the cognitive and non-cognitive skill measures of parents.

As network measure $F N$ we consider both the quantity and the quality of the friendship network of the parent. As measure for network quantity we use the number of connections and make a distinction between in-degree, out-degree and reciprocated friendship connections. ${ }^{13}$ As measure of network quality we use the average earnings scores of the parents' friends. To show how observed characteristics affect the impact of friendship ties, we consecutively extend the set of control variables in the regression equation. For each friendship measure, the sample is restricted to individuals for whom information on the full set of characteristics is available. Furthermore, we perform the analysis separately for female and male respondents to account for potential gender differences.

Number of friends (size of the network) Table 4 reports estimates for six different specifications, where we use the total number of friendship connections as measure for the size of the network. In column (1) we show the marginal friendship effect in a model without other covariates. The coefficient is significantly different from zero and indicates that one additional friendship connection of the parent is associated with an earnings score increase of the child of 0.534 percentage points. The estimated association, however, is very small given an earnings-score standard deviation of approx-

\footnotetext{
${ }^{13}$ All estimates are based on the corrected friendship measures. Marginal effects for the (uncorrected) observed number of connections are summarized in the appendix (Table A.2).
} 
imately 20 percentage points. In columns (2) to (5) we add characteristics to the regression model that are arguably exogenous, including the child's gender and age, and measures of parents' cognitive and non-cognitive skills. In column (2) we find that adding child characteristics does not alter the estimated network coefficient. The estimates for gender and age are nonetheless statistically significant and similar to those found in most other wage regressions; that is, the earnings score is lower for women and concave in age. In column (3) we also find that including personality traits does no change the friendship effect. Of the five personality traits, only agreeableness and openness to experiences affect the child's earnings score in a statistical significant way. In column (4) we add parental IQ and find that the total number of friendship connections continues to have a small but marginally significant effect on the child's earnings score. Parental IQ itself has a significantly positive impact, which suggests that high IQ parents have, on average, more high-school friends as well as more children who are more successful on the labor market.

In columns (5) and (6) we also control for the earnings score and years of education of parents. Including these parental characteristics as control variables in the earnings-score regressions is debatable. In case parents' friends help parents to find jobs in higher paying occupations, or influence their educational qualifications that enable parents to work in higher paying occupations, the parents' educational attainment and earnings scores are outcome variables rather than control variables. Nonetheless, if we control for the parents' earnings score and years of education, we find that the estimated network coefficient does not change much. The impact of parents' friends on the child earnings score is still insignificantly small, holding parental education, occupational earnings score, and other characteristics constant. As such, these findings coincide with those from the previous subsection, where the friendship connections of parents had no effect anymore after conditioning on parental outcomes.

Table 5 contains results on the parents' network effect on child earnings 
Table 4: Marginal network size effects on the child's earnings score

\begin{tabular}{|c|c|c|c|c|c|c|}
\hline & (1) & (2) & (3) & (4) & (5) & (6) \\
\hline \multirow[t]{2}{*}{ Total friendship connections } & $0.534^{* * *}$ & $0.536^{* * *}$ & $0.585^{* * *}$ & $0.372^{*}$ & 0.307 & 0.214 \\
\hline & $(0.204)$ & $(0.200)$ & $(0.201)$ & $(0.200)$ & $(0.199)$ & $(0.198)$ \\
\hline \multirow[t]{2}{*}{ Child - Female } & & $-7.959^{* * *}$ & $-7.836^{* * *}$ & $-7.959 * * *$ & $-7.953^{* * *}$ & $-7.967 * * *$ \\
\hline & & $(0.547)$ & $(0.544)$ & $(0.540)$ & $(0.536)$ & $(0.531)$ \\
\hline \multirow[t]{2}{*}{ Child - Age (in 2004) } & & $4.463^{* * *}$ & $4.509^{* * *}$ & $4.251^{* * *}$ & $4.056^{* * *}$ & $3.851^{* * *}$ \\
\hline & & $(1.124)$ & $(1.120)$ & $(1.110)$ & $(1.102)$ & $(1.093)$ \\
\hline \multirow[t]{2}{*}{ Child - Age squared } & & $-0.062^{* * *}$ & $-0.062^{* * *}$ & $-0.058^{* * *}$ & $-0.055^{* * *}$ & $-0.051^{* * *}$ \\
\hline & & $(0.015)$ & $(0.015)$ & $(0.015)$ & $(0.015)$ & $(0.015)$ \\
\hline \multirow[t]{2}{*}{ Parent - Female } & & & -0.0629 & -0.391 & $1.889^{* * *}$ & $1.887^{* * *}$ \\
\hline & & & $(0.579)$ & $(0.575)$ & $(0.627)$ & $(0.621)$ \\
\hline \multirow[t]{2}{*}{ Parent - Extraversion score } & & & 0.353 & $0.627^{* *}$ & $0.608^{* *}$ & $0.614^{* *}$ \\
\hline & & & $(0.281)$ & $(0.280)$ & $(0.278)$ & $(0.276)$ \\
\hline \multirow[t]{2}{*}{ Parent - Agreeableness score } & & & $-1.138^{* * *}$ & $-0.755^{*}$ & -0.623 & -0.536 \\
\hline & & & $(0.390)$ & $(0.388)$ & $(0.386)$ & $(0.383)$ \\
\hline \multirow[t]{2}{*}{ Parent - Conscientiousness score } & & & 0.412 & 0.519 & 0.480 & 0.500 \\
\hline & & & $(0.376)$ & $(0.373)$ & $(0.370)$ & $(0.367)$ \\
\hline \multirow[t]{2}{*}{ Parent - Neuroticism score } & & & -0.331 & -0.0300 & 0.0516 & 0.0640 \\
\hline & & & $(0.277)$ & $(0.276)$ & $(0.274)$ & $(0.272)$ \\
\hline \multirow[t]{2}{*}{ Parent - Openness score } & & & $1.777^{* * *}$ & $1.126^{* * *}$ & $0.691^{* *}$ & 0.178 \\
\hline & & & $(0.311)$ & $(0.315)$ & $(0.316)$ & $(0.318)$ \\
\hline \multirow[t]{2}{*}{ Parent - IQ score } & & & & $0.195^{* * *}$ & $0.151^{* * *}$ & $0.092^{* * *}$ \\
\hline & & & & $(0.020)$ & $(0.020)$ & $(0.021)$ \\
\hline \multirow[t]{2}{*}{ Parent - Earnings score 1992} & & & & & $0.137^{* * *}$ & $0.096^{* * *}$ \\
\hline & & & & & $(0.016)$ & $(0.016)$ \\
\hline \multirow[t]{2}{*}{ Parent - Years of education } & & & & & & $1.124^{* * *}$ \\
\hline & & & & & & $(0.118)$ \\
\hline \multirow[t]{2}{*}{ Intercept } & $34.12^{* * *}$ & $-41.62^{* *}$ & $-46.80^{* *}$ & $-64.03^{* * *}$ & $-60.99 * * *$ & $-52.20^{* *}$ \\
\hline & $(0.729)$ & $(20.89)$ & $(21.02)$ & $(20.90)$ & $(20.75)$ & $(20.60)$ \\
\hline Observations & 5290 & 5290 & 5290 & 5290 & 5290 & 5290 \\
\hline
\end{tabular}

Note - The dependent variable is the child's earnings score measured in 2004. The independent variable of interest is the total number of friendship connections measured in 1992. Regressions contain varying sets of controls. Standard errors are in parentheses; ${ }^{*}$ significant at $10 \%$ level, ${ }^{* *}$ significant at $5 \%$ level, ${ }^{* * *}$ significant at $1 \%$ level. 
scores using the out-degree, the in-degree and the number of reciprocated claims as alternative measures for the size of the friendship network. We find that claimed friendships (out-degree) have a somewhat weaker association with the child's earnings score than received friendship claims (indegree). The number of reciprocated friendships shows the smallest associations, which are also never statistically significant.

Table 6 contains some tests on whether the father's network has another influence on their children than the mother's network. We expect to see differences for a number of reasons. First, respondents of the WLS are asked to report same-sex friends; that is, we only observe the male friends for fathers and female friends for mothers. Second, simple network averages already show that mothers have a larger network than fathers. And third, previous studies report different intergenerational correlations for mothers and fathers (e.g. the review by Haveman and Wolfe, 1995). When we run our network regressions on samples of mothers and fathers separately, we find that the small but positive friendship effects on the earnings score of children are mostly driven by the network of mothers. The network effects of mothers are all positive but get smaller when covariates are added. When we include the full set of covariates, we find that maternal network effects on child earnings scores are insignificantly small, regardless of how friendship connections are measured. The network effects of fathers are, in most specifications, smaller than the network effects of mothers. In case networks are based on out-degree or reciprocated friendship connections, the father network effects turn even slightly negative. ${ }^{14}$

Earnings score of friends (quality of network) We next take another perspective on friendship ties and examine whether network quality, as proxied by the average earnings score of friends, has an impact on the child's

\footnotetext{
${ }^{14}$ We have also tested whether the network effects are different for daughters and sons. The impact of parent friendship ties is only slightly larger when we restrict the sample to sons. Also, our estimates suggest no significant interaction effects between gender of parents' friends and gender of children.
} 
Table 5: Marginal network size effects using several network measures

\begin{tabular}{lcccc}
\hline \hline Number of.. & $(1)$ & $(2)$ & $(3)$ & $(4)$ \\
\hline Total connections & $0.534^{* * *}$ & $0.536^{* * *}$ & $0.372^{*}$ & 0.214 \\
& $(0.204)$ & $(0.200)$ & $(0.200)$ & $(0.198)$ \\
\hline Out-degree & 0.332 & 0.342 & 0.137 & 0.013 \\
& $(0.302)$ & $(0.296)$ & $(0.296)$ & $(0.292)$ \\
\hline Reciprocated & 0.291 & 0.287 & -0.0369 & -0.341 \\
& $(0.523)$ & $(0.512)$ & $(0.524)$ & $(0.516)$ \\
\hline In-degree & $0.475^{* *}$ & $0.471^{* *}$ & 0.336 & 0.175 \\
& $(0.216)$ & $(0.211)$ & $(0.211)$ & $(0.208)$ \\
\hline Child characteristics & & $\checkmark$ & $\checkmark$ & $\checkmark$ \\
Parent characteristics & & & $\checkmark$ & $\checkmark$ \\
Parent outcomes & & & & $\checkmark$ \\
\hline Observations & 5290 & 5290 & 5290 & 5290 \\
\hline \hline
\end{tabular}

Note - The dependent variable is the child's earnings score measured in 2004. The independent variable of interest is the number of friends for four different network measures measured in 1992. Each estimate involves OLS regressions based on one independent network variable with varying sets of controls. Child controls include gender, age and age squared. Parental controls include including gender, five personality traits and IQ test scores. Parental outcomes include earnings score and years of schooling. Standard errors are in parentheses; ${ }^{*}$ significant at $10 \%$ level, ${ }^{* *}$ significant at $5 \%$ level, ${ }^{* * *}$ significant at $1 \%$ level. 


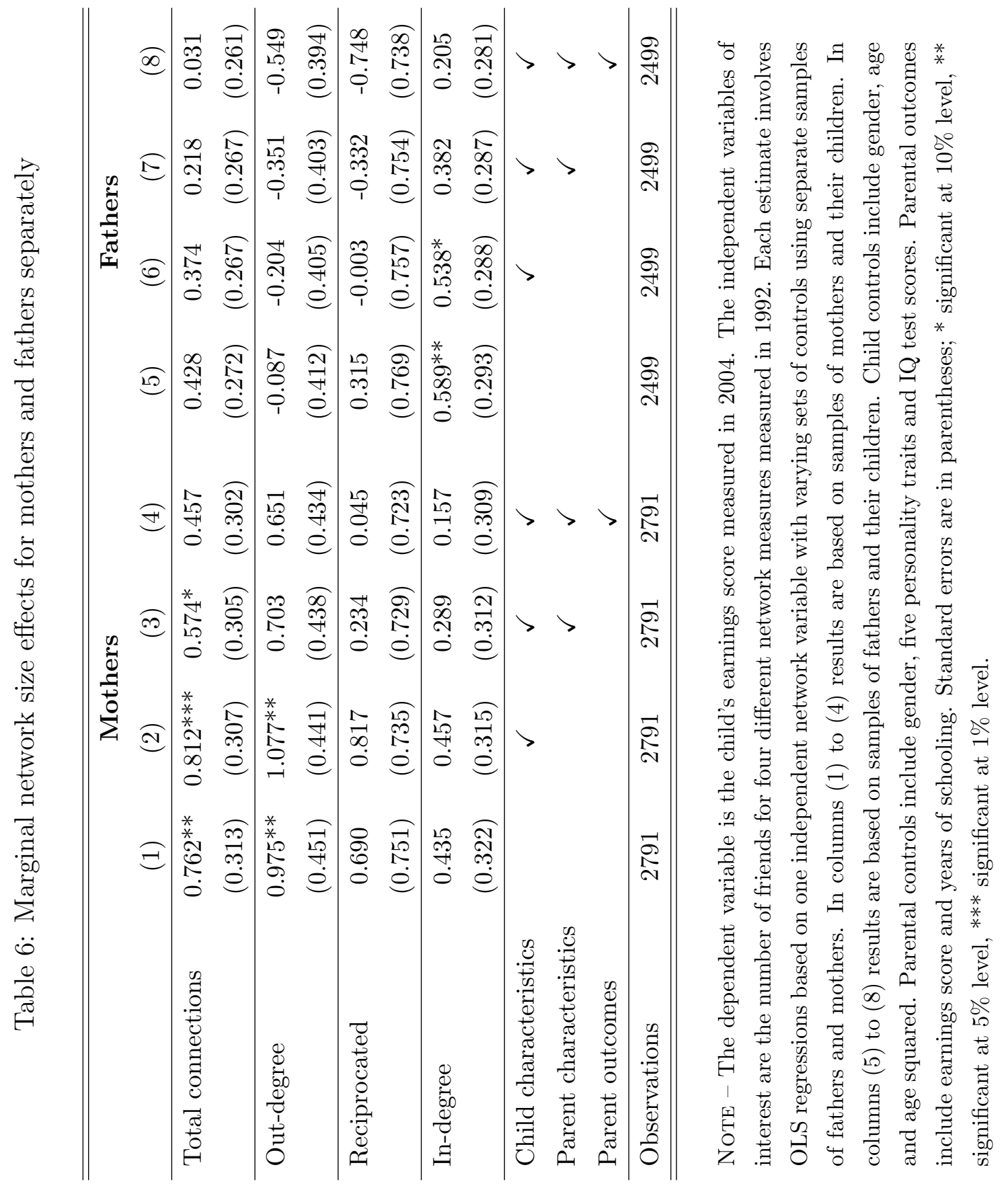


outcome. Because not all claims are observed, the sample size reduces by approximately two-thirds. Tables 7 and 8 present the estimation results for the average earnings score of all connections and for those of the distinct friendship channels (in the same format as before).

Almost all results in Tables 7 and 8 are qualitatively similar to those reported in Tables 5 and 6 . If we do not control for other child and parent characteristics, the average earnings score, regardless of the type of friendship connections, has a significantly positive impact on the earnings score of children even though the network effect is moderate in size. A one percentage point increase in the average earnings score of friends raises the outcome variable by approximately 0.07 percentage points. As before, the network estimates decrease and turn insignificant when we add the child and parent control variables. Estimation results for the different measures for friendship networks do not reveal any considerable heterogeneity. If we look again at the network effects for mothers and fathers separately, we observe similar patterns as before although differences by gender of parent are less pronounced here.

\section{Robustness checks}

Our regression results indicate that parental friendship connections have little, if any, influence on the prospective earnings of children. This is by no means a trivial finding, given the widespread notion that friends of parents provide children with valuable information about job opportunities. We, therefore, perform additional robustness checks to see how sensitive our parental network estimates are to a number of potential threats: network endogeneity, network recall and measurement error, network persistency and the timing of network effects. In examining the impact of each of these threats, we focus attention on network specifications based on out-degree 
Table 7: Marginal network quality effects on the child's earning score

\begin{tabular}{lcccc}
\hline \hline & $(1)$ & $(2)$ & $(3)$ & $(4)$ \\
\hline Total connections & $0.070^{* * *}$ & $0.054^{* * *}$ & 0.026 & 0.006 \\
& $(0.019)$ & $(0.019)$ & $(0.021)$ & $(0.021)$ \\
Observations & 3189 & 3189 & 3189 & 3189 \\
\hline Out-degree & $0.069^{* * *}$ & $0.059^{* * *}$ & 0.028 & 0.010 \\
& $(0.021)$ & $(0.020)$ & $(0.023)$ & $(0.023)$ \\
Observations & 2455 & 2455 & 2455 & 2455 \\
\hline Reciprocated & $0.088^{* * *}$ & $0.077^{* * *}$ & 0.040 & 0.025 \\
& $(0.0286)$ & $(0.028)$ & $(0.031)$ & $(0.030)$ \\
Observations & 1242 & 1242 & 1242 & 1242 \\
\hline In-degree & $0.072^{* * *}$ & $0.053^{* *}$ & 0.023 & 0.004 \\
& $(0.023)$ & $(0.023)$ & $(0.025)$ & $(0.025)$ \\
Observations & 2226 & 2226 & 2226 & 2226 \\
\hline Child characteristics & & $\checkmark$ & $\checkmark$ & $\checkmark$ \\
Parent characteristics & & & $\checkmark$ & $\checkmark$ \\
Parent outcomes & & & $\checkmark$ \\
\hline \hline
\end{tabular}

Note - The dependent variable is the child's earnings score measured in 2004. The independent variable is the average earnings score of friends for four different network measures measured in 1992. Each estimate involves OLS regressions based on one independent network variable with varying sets of controls. Child controls include gender, age and age squared. Parental controls include gender, five personality traits and IQ test scores. Parental outcomes include earnings score and years of schooling. Standard errors are in parentheses; * significant at $10 \%$ level, ${ }^{* *}$ significant at $5 \%$ level, ${ }^{* * *}$ significant at $1 \%$ level. 


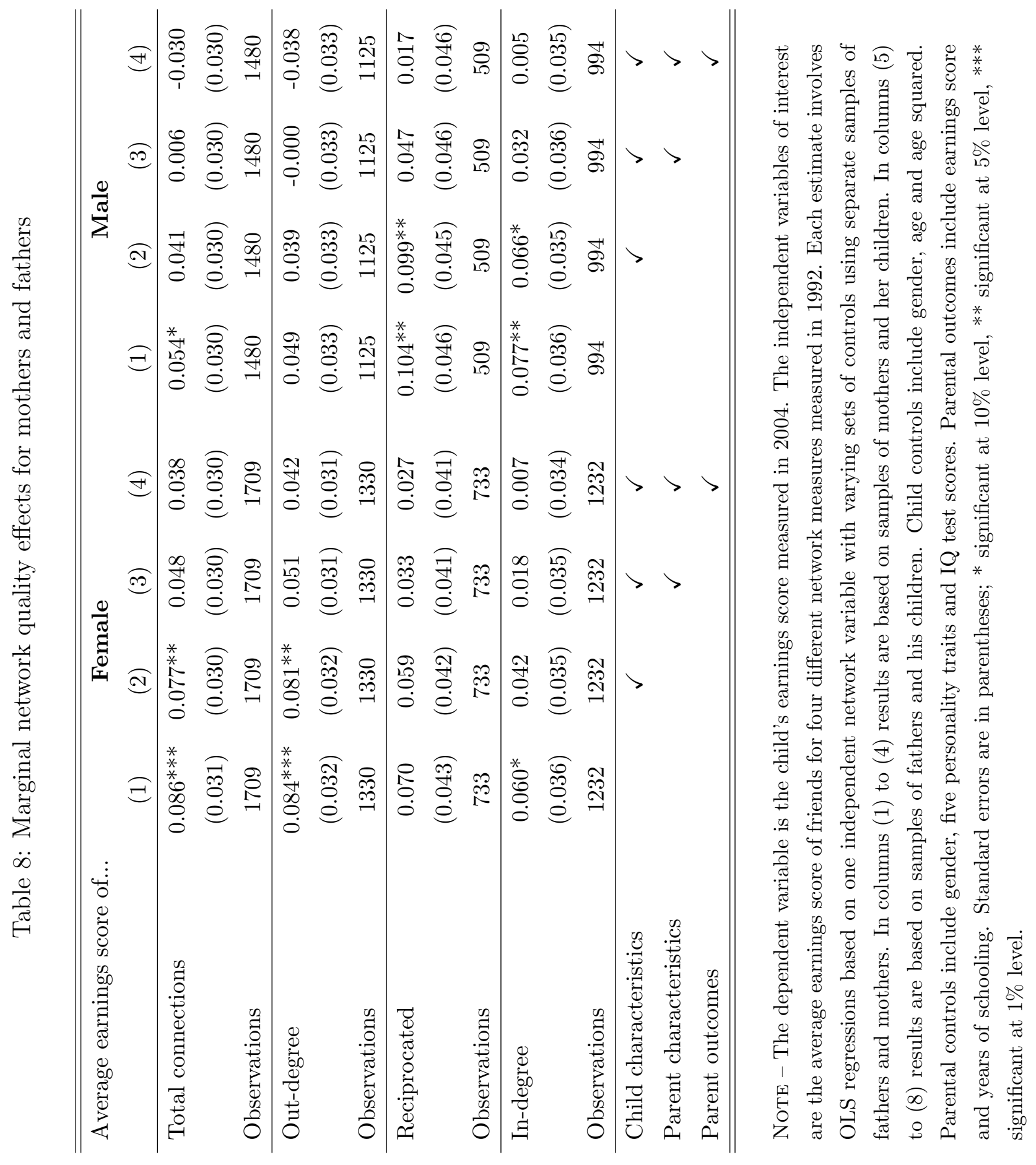


friendship connections for reasons of brevity. ${ }^{15}$

Network endogeneity. One natural concern is that size and characteristics of friendship networks are endogenously determined. If there are unobserved factors that enable parents to form friendships and help their children to obtain better job qualifications, our network effects are biased and probably too high. In our empirical setup, however, this appears less of a concern when interpreting the absence of parental network effects.

To explore the role of these unobserved factors in more detail, we repeat the friendship analysis in the context of a friendship fixed effects model. If high-school friends are similar in most characteristics but differ in the number and type of additional friends they have, we can reduce the impact of these unobserved factors by taking differences between the friends' children. In our analysis we focus on differences between parents and their first claimed friends, which excludes by construction all parents who claim to have no friends in the WLS. In total, our sample consists of 926 friendship pairs. ${ }^{16}$

Table 9, Panel B, reports the fixed effects estimates for the out-degree and the average earnings score of friends. Comparing these estimates with our baseline estimates, reported in Panel A, we find that almost all the estimated network effects are slightly negative. We also find that the fixed effects estimates do not change much when we add other control variables. This is not surprising. If friends indeed share (some of) the confounding factors that may bias our network results, we should find that our fixed effects estimates are insensitive to the inclusion of cognitive and non-cognitive skill measures. Because the friendship fixed effect network estimates continue to be small and statistically insignificant, we do not think that unobserved factors (shared by friends) can explain the weak network effects found in the previous section.

\footnotetext{
${ }^{15}$ We have also compared the results with those obtained for the network measures based on in-degree, total and reciprocated connections. We found no systematic differences. These sensitivity results are available upon request.

${ }^{16}$ Even though some claims are reciprocated, each friendship pair is included only once in the analysis.
} 


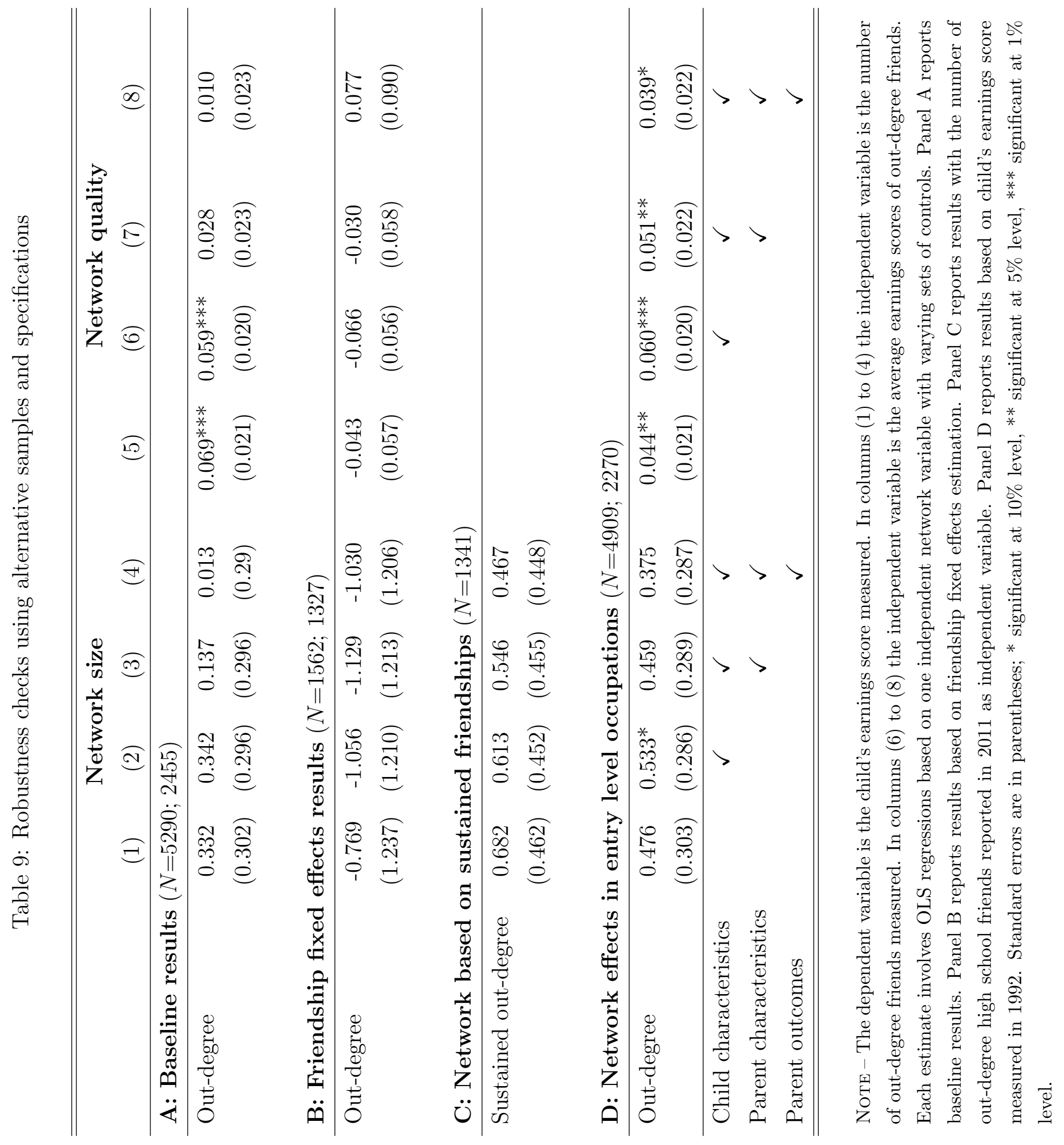


Network measurement error. Another concern is measurement error in our network measures. We construct the measures based on information about high-school friends that is collected 18 years after high-school graduation. When parents make mistakes or have difficulties in recalling who their best friends are, there is measurement error in our network measure. If the measurement error is random, i.e. unrelated to the true network measure, the estimated marginal effects are biased towards zero (classical measurement error). To test for the impact of this error, we treat the friendship network measure as a continuous variable and adjust the parameter estimates and standard errors by imposing predetermined noise to signal ratios in estimation.

Table 10 presents the marginal effects of the corrected number of total friendship connections on the earnings score of children for different noise to signal ratios (which are reported in column (3)). The estimation result show only a modest increase in the true network effect for increasing degrees of measurement error $(\operatorname{VAR}(U))$. Even if half of the observed variation can be explained by measurement error, the network estimate suggest that one additional friend increases the earnings score by only 1.154 percentage points, which is still small given a earnings score standard deviation of around 20 percentage points. This simulation exercise shows that small estimates cannot be explained by classical measurement error in the friendship variables. Taking into account that the marginal effect further decreases when we control for parent covariates, the underlying error must be inconceivably high to obtain sizeable estimates.

Network persistency. It is also clear to what extent parents are still in contact with the high-school friends later in life. Although friends who kept in touch after high school are more likely to be reported, it is reasonable to assume that some of the claimed connections have not been maintained. As those friends are unlikely to affect the labor-market outcomes of each other's children, they will, by construction, lower the average impact of friendship 
Table 10: Measurement error and marginal network size effects

\begin{tabular}{cccccc}
\hline \hline$V A R(U)$ & $V A R\left(F N^{*}\right)$ & $\frac{V A R(U)}{V A R(F N)}$ & $\beta$ & $S E$ & $\frac{\beta}{S E(\beta)}$ \\
\hline 0.0 & 1.86 & $0 \%$ & 0.534 & 0.204 & 2.61 \\
0.2 & 1.66 & $11 \%$ & 0.599 & 0.216 & 2.77 \\
0.4 & 1.46 & $22 \%$ & 0.681 & 0.231 & 2.95 \\
0.6 & 1.26 & $32 \%$ & 0.788 & 0.248 & 3.18 \\
0.8 & 1.06 & $43 \%$ & 0.937 & 0.271 & 3.46 \\
1.0 & 0.86 & $54 \%$ & 1.154 & 0.300 & 3.84 \\
1.2 & 0.66 & $65 \%$ & 1.502 & 0.343 & 4.38 \\
1.4 & 0.46 & $75 \%$ & 2.150 & 0.410 & 5.24 \\
1.6 & 0.26 & $86 \%$ & 3.785 & 0.544 & 6.96 \\
1.8 & 0.06 & $97 \%$ & 15.788 & 1.111 & 14.21 \\
\hline \hline
\end{tabular}

Note - The dependent variable is the child's earnings score measured in 2004. The independent variable is the total number of friends measured in 1992. Results are reported for different noise-to-signal ratios. Column (1) reports the assumed variance of the measurement error $\operatorname{VAR}(U)$. Column (2) reports the variance of the true number of friends $\operatorname{VAR}\left(F N^{*}\right)$, which equals $\operatorname{VAR}(F N)$ $\operatorname{VAR}(U)$. Column (3) reports the noise-to-signal ratio. Column (4) to (6) report corresponding network effects, together with standard errors and t-values. 
connections. To address this concern, we rely on the most recent survey held under the WLS respondents. In 2011 the subsample of respondents who had at least one reciprocal friend in 1975 (complemented with a 15\% random draw of other WLS respondents) were asked again to report up to three same-sex high school friends they are still in contact with. This sample contains 1558 observations. While the questionnaire does not explicitly refer to friendship claims in 1975, it provides an additional measure of network connections that allows us to draw inference on the importance of high-school connections later in life. Compared to the initial out-degree, the average number of friendship claims decreases from 2.25 to 1.42 . About $40 \%$ of all the parents report to have the same number of friends in both waves. The correlation between the 1975 and 2011 out-degree equals 0.20 .

Table 9, Panel C, tests whether sustained connections have a stronger impact on the earnings score of children. We find that the effect of sustained friendships is larger in all specifications and less sensitive to the inclusion of control variables. Since not all high school friendships have been maintained until 2011, it makes sense that the estimated network effect is somewhat larger among the long lasting friends of parents. The estimates, however, remain small and statistically insignificant, which confirms that high school friends of parents have no substantial effect on the earnings score of children.

Network effects in entry level occupations. Our analysis has focused on the earnings score of children in 2004, when most children are about 38 years old and likely work in their primary lifetime occupation. However, it is possible that friendship networks of parents are stronger at earlier stages of the child's occupational career. Job-market entrants may benefit more from social networks of their parents because they are less good connected themselves and less informed about employment prospects than older workers. Also employers are less able to evaluate the productivity of young workers and, thus, rely more often on informal referrals (see Hensvik and Nordström Skans (2013)). Or children might have more contact with their 
parents at young ages and can better benefit from their friendship network.

To detect whether network effects are stronger in entry level occupations, we repeat our analysis using the earnings score of children measured in 1992. At this early stage, most children are about 26 years old, just finished their education, and started working in their first occupation. ${ }^{17}$ Table 9, Panel $\mathrm{D}$, reports the network effect estimates for entry level occupations using the earnings score of children in 1992 as outcome variable. We find that the number of friends as well as the average earnings scores of friends have a somewhat stronger impact 12 years earlier. The estimates are also less sensitive to the inclusion of parent covariates, leading to higher and in part marginally significant effects. Controlling for child characteristics, one additional friendship connection increases the earning score of children in 1992 significantly by 0.533 percentage points. While not reported in the table, we find for the other network measures (based on total, in-degree and reciprocal friendship connections) estimates that are similar in size and in most cases statistically significant. Also the earnings score of friendship connections shows somewhat stronger and statistically significant effects 12 years earlier. In the richest specification, we find that a one standard deviation increase raises the earnings score of children by approximately 0.765 percentage points. Compared to the overall variation in earnings scores, however, the network effects in entry level occupations are still modest.

\section{Conclusion}

Motivated by the idea that children may incur labor-market benefits from their parents' social network, this study makes a first attempt to empirically test whether children are better off because their parents have stronger social networks. Using data on high-school connections of parents, we find evidence

\footnotetext{
${ }^{17}$ It is possible that some of the children in our sample have not finished their university education yet and report to work in a part-time or student jobs. However, the WLS occupations are only reported if children have worked at least six months in the same occupation.
} 
that children are slightly more likely to work in the same occupation as their parent's friends, but this association disappears once we take into account the similarity in occupational choices of children and parents. When we analyze the network impact on the occupational earnings score of children (which quantifies the average payoff by occupations), we also find that neither larger nor better friendship networks of parents significantly increase the children's earnings score. Robustness tests confirm these results, showing that threats to the empirical approach such as network endogeneity, network persistency and network measurement error cannot explain the absence of substantial network effects.

These findings together suggest children do not work in occupations that pay higher wages because of their parents' friendship network. Our findings, however, are not the result of a well-defined natural experiment and must be interpreted with care. We can think of three possible interpretations. The first one is a selection interpretation; that is, children raised by parents with many high-school friends are different from children raised by parents with few high-school friends. This is consistent with the notion of biased network estimates in which omitted variables relevant to the occupational choice of children are negatively related to their parents' friendship network. We have little indication of what these variables might be. Our sensitivity analysis rules out a number of plausible candidate variables. The second interpretation takes our findings at face value; that is, children do not take advantage of their parents' friends. The recent findings of Kramarz and Nordström Skans (2014) using network data from Sweden supports this view. The third interpretation relies on heterogeneous network effects; that is, we measure an offsetting average where some children experience positive network effects and other children experience negative earnings effects. In this case friends of parents are indeed helpful in mediating children into occupations where some children benefit and work in occupations of better quality with higher paying wages while other children just accept offers to escape unemployment and work in occupations less fit for their skills. Evidence about small but 
negative network effects have been discussed in Bentolila et al. (2010) and Pellizzari (2010). Our friendship fixed effects estimates, which show network effects that are modest but negative, also appear consistent with the latter interpretation.

In our view, it is difficult to say whether the zero network effect represents an effect that holds for all children or represents an average effect of positive and negative effects that offset each other. Given the limited nature of our friendship network information, our estimates cannot make a distinction between the two interpretations. Nonetheless, we are confident enough to conclude that, on average, children do not take advantage of their parents' friends. 


\section{References}

Behrman, J. R. and Rosenzweig, M. R. (2002). Does increasing women's schooling raise the schooling of the next generation? American Economic Review, 92(1):323-334.

Bentolila, S., Michelacci, C., and Suarez, J. (2010). Social contacts and occupational choice. Economica, 77(305):20-45.

Björklund, A. and Jäntti, M. (1997). Intergenerational income mobility in sweden compared to the united states. American Economic Review, 87(5):1009-1018.

Bramoullé, Y., Djebbari, H., and Fortin, B. (2009). Identification of peer effects through social networks. Journal of Econometrics, 150(1):41-55.

Cappellari, L. and Tatsiramos, K. (2013). With a little help from my friends? quality of social networks, job finding rates and job match quality. Working Paper.

Cingano, F. and Rosolia, A. (2012). People i know: job search and social networks. Journal of Labor Economics, 30(2):291-332.

Conti, G., Galeotti, A., Müller, G., and Pudney, S. (2013). Popularity. Journal of Human Resources, 48(4):1072-1094.

Costa Jr, P. T. and McCrae, R. R. (1992). Four ways five factors are basic. Personality and Individual Differences, 13(6):653-665.

Edin, P.-A., Fredriksson, P., and Åslund, O. (2003). Ethnic enclaves and the economic success of immigrants - evidence from a natural experiment. Quarterly Journal of Economics, 118(1):329-357.

Ennett, S. T. and Bauman, K. E. (1996). Adolescent social networks school, demographic, and longitudinal considerations. Journal of Adolescent Research, 11(2):194-215. 
Goldberg, L. R. (1990). An alternative "description of personality": The big-five factor structure. Journal of Personality and Social Psychology, 59(6):1216-1229.

Granovetter, M. S. (1973). The strength of weak ties. American Journal of Sociology, 78(6):1360-1380.

Haider, S. and Solon, G. (2006). Life-cycle variation in the association between current and lifetime earnings. American Economic Review, 96(4):1308-1320.

Haveman, R. and Wolfe, B. (1995). The determinants of children's attainments: A review of methods and findings. Journal of Economic Literature, 33(4):1829-1878.

Hensvik, L. and Nordström Skans, O. (2013). Networks and youth labor market entry. IFAU Working Paper 2013:23.

Holmlund, H., Lindahl, M., and Plug, E. (2011). The causal effect of parents' schooling on children's schooling: A comparison of estimation methods. Journal of Economic Literature, 49(3):615-651.

Holzer, H. J. (1987). Informal job search and black youth unemployment. American Economic Review, 77(3):446-452.

Holzer, H. J. (1988). Search method use by unemployed youth. Journal of Labor Economics, 6(1):1-20.

Ioannides, Y. M. and Loury, L. D. (2004). Job information networks, neighborhood effects and inequality. Journal of Economic Literature, 42(4):1056-1093.

Jackson, M. O. (2010). An overview of social networks and economic applications. In Benhabib, J., Bisin, A., and Jackson, M. O., editors, Handbook of Social Economics, volume 1, chapter 12, pages 511-585. Elsevier Science. 
John, O. P., Donahue, E. M., and Kentle, R. L. (1991). The big five inventoryversions 4a and 54. Berkeley: University of California, Berkeley, Institute of Personality and Social Research.

Krackhardt, D. (1992). The strength of strong ties: The importance of philos in organizations. Networks and organizations: Structure, form, and action, 216:239.

Kramarz, F. and Nordström Skans, O. (2014). When strong ties are strong - networks and youth labor market entry. Review of Economic Studies, (81):1164-1200.

Laband, D. N. and Lentz, B. F. (1992). Self-recruitment in the legal profession. Journal of Labor Economics, 10(2):182-201.

Lentz, B. F. and Laband, D. N. (1989). Why so many children of doctors become doctors: Nepotism vs. human capital transfers. Journal of Human Resources, 24(3):396-413.

Manski, C. F. (1993). Identification of endogenous social effects: The reflection problem. Review of Economic Studies, 60(3):531-542.

Marmaros, D. and Sacerdote, B. (2006). How do friendships form? Quarterly Journal of Economics, 121(1):79-119.

Olivetti, C., Patacchini, E., and Zenou, Y. (2013). Mothers, friends and gender identity. NBER Working Paper No. 19610.

Pellizzari, M. (2010). Do friends and relatives really help in getting a good job? Industrial and labor relations review, 63(3):494-510.

Plug, E. (2004). Estimating the effect of mother's schooling on children's schooling using a sample of adoptees. American Economic Review, 94(1):358-368.

Rees, A. (1966). Information networks in labor markets. American Economic Review, 56(1/2):559-566. 
Solon, G. (1992). Intergenerational income mobility in the united states. American Economic Review, 82(3):393-408.

Topa, G. (2001). Social interactions, local spillovers and unemployment. Review of Economic Studies, 68(2):261-295.

\section{Appendix}




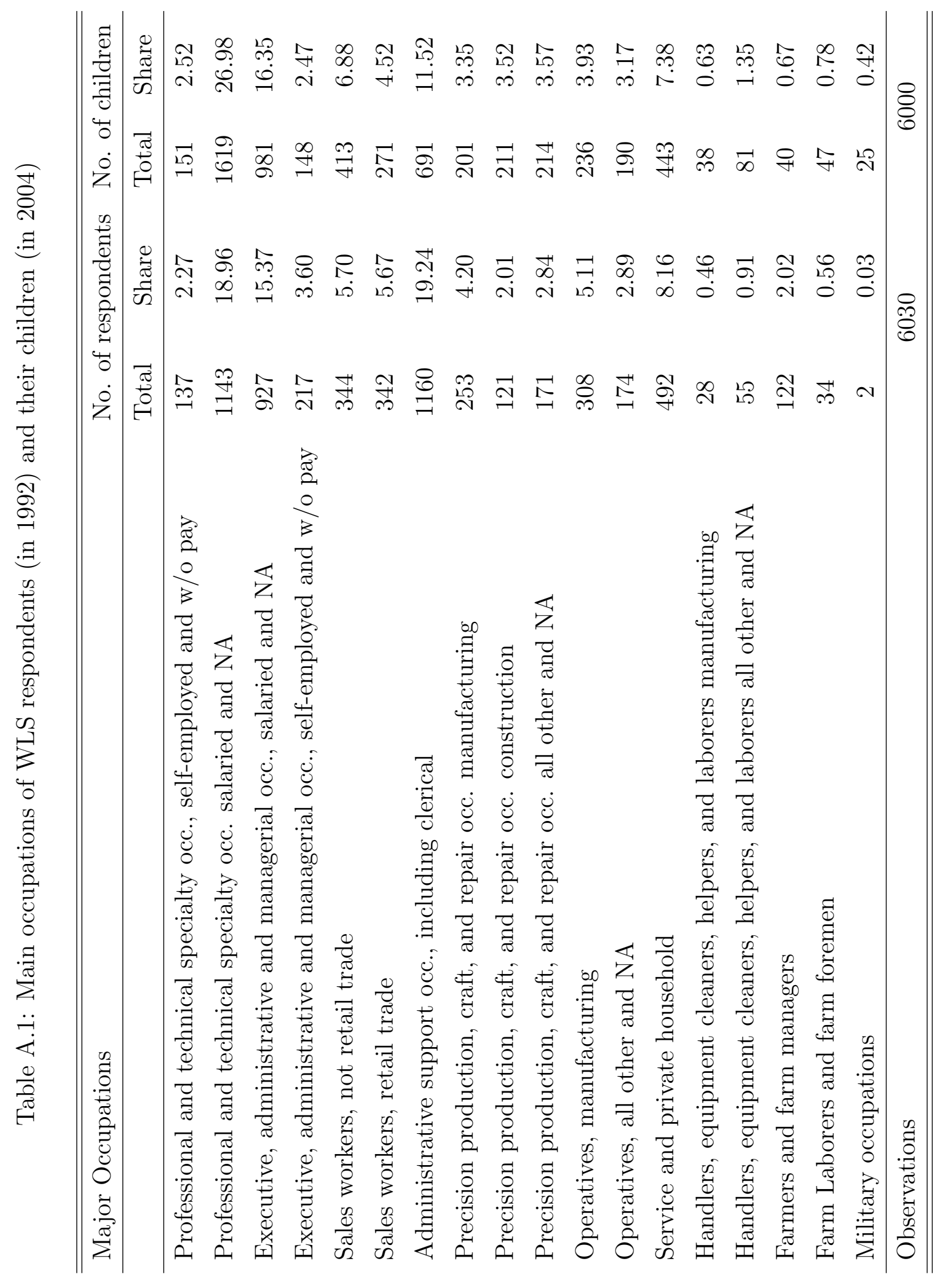


Table A.2: Marginal effects on the child's earnings score (Raw and corrected friendship measures)

\begin{tabular}{|c|c|c|c|c|c|}
\hline Number of.. & & (1) & $(2)$ & $(3)$ & $(4)$ \\
\hline \multirow{4}{*}{ Recipr. connections } & \multirow{2}{*}{ raw } & 0.250 & 0.189 & 0.0665 & -0.157 \\
\hline & & $(0.518)$ & $(0.507)$ & $(0.503)$ & $(0.495)$ \\
\hline & \multirow{2}{*}{ corrected } & 0.291 & 0.287 & -0.0369 & -0.341 \\
\hline & & $(0.523)$ & $(0.512)$ & $(0.524)$ & $(0.516)$ \\
\hline \multirow{4}{*}{ In-degree } & \multirow{2}{*}{ raw } & $0.838 * * *$ & $0.816^{* * *}$ & $0.588^{*}$ & 0.342 \\
\hline & & $(0.318)$ & $(0.312)$ & $(0.310)$ & $(0.305)$ \\
\hline & \multirow{2}{*}{ corrected } & $0.475^{* *}$ & $0.471^{* *}$ & 0.336 & 0.175 \\
\hline & & $(0.216)$ & $(0.211)$ & $(0.211)$ & $(0.208)$ \\
\hline \multirow{4}{*}{ Total connections } & \multirow{2}{*}{ raw } & $0.633^{* * *}$ & $0.640^{* * *}$ & $0.413^{*}$ & 0.241 \\
\hline & & $(0.240)$ & $(0.235)$ & $(0.236)$ & $(0.232)$ \\
\hline & \multirow{2}{*}{ corrected } & $0.534^{* * *}$ & $0.536^{* * *}$ & $0.372^{*}$ & 0.214 \\
\hline & & $(0.204)$ & $(0.200)$ & $(0.200)$ & $(0.198)$ \\
\hline \multicolumn{2}{|l|}{ Child characteristics } & No & Yes & Yes & Yes \\
\hline \multicolumn{2}{|l|}{ Parent characteristics } & No & No & Yes & Yes \\
\hline \multicolumn{2}{|l|}{ Parent outcomes } & No & No & No & Yes \\
\hline \multicolumn{2}{|l|}{ Observations } & 5290 & 5290 & 5290 & 5290 \\
\hline
\end{tabular}

Note - The dependent variable is the child's earnings score measured in 2004. The independent variable of interest is number of friends for four different network measures measured in 1992 before and after correction. Each estimate involves OLS regressions based on one independent network variable with varying sets of controls. Child controls include gender, age and age squared. Parental controls include including gender, five personality traits and IQ test scores. Parental outcomes include earnings score and years of schooling. Standard errors are in parentheses; * significant at $10 \%$ level, ** significant at $5 \%$ level, ${ }^{* * *}$ significant at $1 \%$ level. 
Table A.3: Marginal effects on the child's earnings score (FE-analysis)

\begin{tabular}{lcccc}
\hline \hline Number of.. & $(1)$ & $(2)$ & $(3)$ & $(4)$ \\
\hline Total connections & -0.0153 & -0.000448 & -0.0974 & -0.107 \\
& $(0.475)$ & $(0.465)$ & $(0.474)$ & $(0.470)$ \\
\hline Out-degree & -0.769 & -1.056 & -1.129 & -1.030 \\
& $(1.237)$ & $(1.210)$ & $(1.213)$ & $(1.206)$ \\
\hline Reciprocated & 0.693 & 0.521 & 0.383 & 0.325 \\
& $(1.798)$ & $(1.760)$ & $(1.763)$ & $(1.752)$ \\
\hline In-degree & 0.121 & 0.159 & 0.0844 & 0.0603 \\
& $(0.433)$ & $(0.424)$ & $(0.430)$ & $(0.427)$ \\
\hline Child characteristics & No & Yes & Yes & Yes \\
Parent characteristics & No & No & Yes & Yes \\
Parent outcomes & No & No & No & Yes \\
\hline
\end{tabular}

Note - The dependent variable is the child's earnings score measured in 2004. The independent variable of interest is the number of friends for four different network measures measured in 1992. Each estimate involves FE regressions based on one independent network variable with varying sets of controls. Child controls include gender, age and age squared. Parental controls include five personality traits and IQ test scores. Parental outcomes include earnings score and years of schooling. Standard errors are in parentheses; * significant at $10 \%$ level, ** significant at $5 \%$ level, *** significant at $1 \%$ level. 
Table A.4: Marginal effects on the child's earnings score (FE-analysis)

\begin{tabular}{lcccc}
\hline \hline Av. earnings score of... & $(1)$ & $(2)$ & $(3)$ & $(4)$ \\
\hline Total connections & $-0.170^{* * *}$ & $-0.191^{* * *}$ & $-0.159^{* * *}$ & -0.122 \\
& $(0.0572)$ & $(0.0563)$ & $(0.0582)$ & $(0.0999)$ \\
\hline Observations & 1538 & 1538 & 1538 & 1538 \\
\hline Out-degree & -0.0430 & -0.0656 & -0.0303 & 0.0769 \\
& $(0.0571)$ & $(0.0560)$ & $(0.0584)$ & $(0.0900)$ \\
\hline Observations & 1327 & 1327 & 1327 & 1327 \\
\hline Reciprocated & -0.0834 & $-0.108^{*}$ & -0.0883 & -0.125 \\
& $(0.0614)$ & $(0.0599)$ & $(0.0629)$ & $(0.190)$ \\
\hline Observations & 921 & 921 & 921 & 921 \\
\hline In-degree & -0.102 & $-0.117^{*}$ & -0.0972 & -0.0639 \\
& $(0.0632)$ & $(0.0613)$ & $(0.0630)$ & $(0.0932)$ \\
\hline Observations & 1270 & 1270 & 1270 & 1270 \\
\hline Child characteristics & No & Yes & Yes & Yes \\
Parent characteristics & No & No & Yes & Yes \\
Parent outcomes & No & No & No & Yes \\
\hline \hline
\end{tabular}

Note - The dependent variable is the child's earnings score measured in 2004. The independent variable is the average earnings score of friends for four different network measures measured in 1992. Each estimate involves FE regressions based on one independent network variable with varying sets of controls. Child controls include gender, age and age squared. Parental controls include five personality traits and IQ test scores. Parental outcomes include earnings score and years of schooling. Standard errors are in parentheses; * significant at $10 \%$ level, ** significant at $5 \%$ level, ${ }^{* * *}$ significant at $1 \%$ level. 
Table A.5: Marginal effects on the child's earning score in 1992

\begin{tabular}{lcccc}
\hline \hline Number of.. & $(1)$ & $(2)$ & $(3)$ & $(4)$ \\
\hline Total connections & $0.595^{* * *}$ & $0.571^{* * *}$ & $0.495^{* *}$ & $0.417^{* *}$ \\
& $(0.205)$ & $(0.194)$ & $(0.195)$ & $(0.194)$ \\
\hline Out-degree & 0.476 & $0.533^{*}$ & 0.459 & 0.375 \\
& $(0.303)$ & $(0.286)$ & $(0.289)$ & $(0.287)$ \\
\hline Reciprocated & 0.835 & 0.727 & 0.668 & 0.497 \\
& $(0.524)$ & $(0.496)$ & $(0.509)$ & $(0.506)$ \\
\hline In-degree & $0.565^{* * *}$ & $0.489^{* *}$ & $0.427^{* *}$ & $0.355^{*}$ \\
& $(0.217)$ & $(0.205)$ & $(0.206)$ & $(0.204)$ \\
\hline Child characteristics & No & Yes & Yes & Yes \\
Parent characteristics & No & No & Yes & Yes \\
Parent outcomes & No & No & No & Yes \\
\hline & 4909 & 4909 & 4909 & 4909 \\
\hline \hline
\end{tabular}

Note - The dependent variable is the child's earnings score measured in 1992. The independent variable of interest is the number of friends for four different network measures measured in 1992. Each estimate involves OLS regressions based on one independent network variable with varying sets of controls. Child controls include gender, age and age squared. Parental controls include including gender, five personality traits and IQ test scores. Parental outcomes include earnings score and years of schooling. Standard errors are in parentheses; ${ }^{*}$ significant at $10 \%$ level, ${ }^{* *}$ significant at $5 \%$ level, ${ }^{* * *}$ significant at $1 \%$ level. 
Table A.6: Marginal effects on the child's earning score in 1992

\begin{tabular}{lcccc}
\hline \hline Average earnings score of... & $(1)$ & $(2)$ & $(3)$ & $(4)$ \\
\hline Total connections & $0.0402^{* *}$ & $0.0632^{* * *}$ & $0.0470^{* *}$ & 0.0328 \\
& $(0.0192)$ & $(0.0184)$ & $(0.0207)$ & $(0.0207)$ \\
Observations & 2943 & 2943 & 2943 & 2943 \\
\hline Out-degree & $0.044^{* *}$ & $0.060^{* * *}$ & $0.051^{* *}$ & $0.039^{*}$ \\
& $(0.021)$ & $(0.020)$ & $(0.022)$ & $(0.022)$ \\
Observations & 2270 & 2270 & 2270 & 2270 \\
\hline Reciprocated & $0.0608^{* *}$ & $0.0691^{* *}$ & 0.0430 & 0.0300 \\
& $(0.0291)$ & $(0.0276)$ & $(0.0304)$ & $(0.0304)$ \\
Observations & 1161 & 1161 & 1161 & 1161 \\
\hline In-degree & 0.0353 & $0.0591^{* * *}$ & 0.0342 & 0.0210 \\
& $(0.0232)$ & $(0.0221)$ & $(0.0245)$ & $(0.0245)$ \\
Observations & 2066 & 2066 & 2066 & 2066 \\
\hline Child characteristics & No & Yes & Yes & Yes \\
Parent characteristics & No & No & Yes & Yes \\
Parent outcomes & No & No & No & Yes \\
\hline \hline
\end{tabular}

Note - The dependent variable is the child's earnings score measured in 1992. The independent variable is the average earnings score of friends for four different network measures measured in 1992. Each estimate involves OLS regressions based on one independent network variable with varying sets of controls. Child controls include gender, age and age squared. Parental controls include gender, five personality traits and IQ test scores. Parental outcomes include earnings score and years of schooling. Standard errors are in parentheses; ${ }^{*}$ significant at $10 \%$ level, ${ }^{* *}$ significant at $5 \%$ level, ${ }^{* * *}$ significant at $1 \%$ level. 